\title{
TOWARDS A BETTER UNDERSTANDING OF ORDER ACCEPTANCE
}

\author{
Hans A. ten Kate, University of Groningen, NL
}

This paper concerns a conceptual research on the comparison of two extreme approaches for order acceptance. It focusses on the interaction of order acceptance and production scheduling at an operational level. In the process industries, demand is often as high as or even higher than the available production capacity, while it is impossible to increase the available capacity. In combination with tendencies towards, on the one hand, an increased product variety and, on the other hand, shorter lead times, this has led to a situation in which order acceptance has more and more obtained a central position in production control.

As mentioned, the goal of this research is the comparison of two extreme approaches for order acceptance. In the first approach, a hierarchical approach, the decision whether or not to accept an order is based on aggregate characteristics of the set of already accepted orders. The production schedule is periodically updated for the orders accep:ed in the last period. Order acceptance and production scheduling take place on different levels of the planning hierarchy.

In the second approach, a so-called scheduling-oriented approach, order acceptance and production scheduling are integrated. The decision whether or not to accept the order is taken by determining a good production schedule which includes the new order. If this new schedule is acceptable, the order can be accepted. obviously, in this approach order acceptance and production scheduling are on the same level in the planning hierarchy.

For a situation which is based on some of the main characteristics of process industries, both approaches for order acceptance are compared by means of a simulation model. Numerical results on a number of performance measures for both approaches will be presented for various scenarios. 